\title{
Breed Related Hospital Prevalence of Theileria annulata infection in Cattle-calves Confirmed by Nested Polymerase Chain Reaction in Bikaner District of Rajasthan, India
}

\author{
Pavan Goyal* and Anju Chahar
}

Department of Epidemiology and Preventive Veterinary Medicine, College of Veterinary and Animal Science, Rajasthan University of Veterinary and Animal Sciences, Bikaner-334 001, Rajasthan, India

*Corresponding author

A B S T R A C T

Keywords

Theileria annulata, Cattle-calves, DNA, nPCR, Cross bred, Prevalence

Article Info

Accepted:

24 January 2018

Available Online:

10 February 2018
One hundred cattle-calves, out of which 37 cross bred and 63 indigenous, were screened for Theileria annulata infection during October-2015 to September-2016 brought to Teaching Veterinary Clinical Complex, College of Veterinary and Animal Science, Bikaner. Blood samples were collected in ethylene diamine tetra acetic acid (EDTA @ $1 \mathrm{mg} / \mathrm{ml}$ ) vacutainers from all the suspected cattle-calves for genomic DNA isolation and subjected for confirmatory diagnosis by nested polymerase chain reaction (nPCR). By nPCR, 19 cross bred and 22 indigenous cattle-calves were found positive for Theileria annulata infection. Thus, the prevalence of Theileria annulata infection in cross bred and indigenous cattle-calves was $51.35 \%(19 / 37)$ and $34.92 \%(22 / 63)$, respectively.

\section{Introduction}

Tropical theileriosis, also known as Mediterranean coast fever, is an extremely fatal and debilitating tick-transmitted disease infecting cattle (Santos et al., 2013). This hemoparasitic infection is caused by Theileria annulata and is responsible for substantial production losses (Gharbi et al., 2011). About 250 million cattle are at risk to Tropical theileriosis worldwide (Erdemir et al., 2012). This intracellular infection inflicts economic burden on cattle breeders in terms of mortality and morbidity as well as expenses spent on prophylactic measures against disease and treatment (Durrani et al., 2008). Theileria annulata was described in Transcaucasian cattle in 1904 and was first named Piroplasma annulatum. It was reclassified as $T$. annulata after identification of schizont stage in its lifecycle (Weir, 2006).

Theileria parasites enter the bovine host during tick feeding as sporozoites, which rapidly invade mononuclear leukocytes. Here, they mature into macroschizonts and induce 
proliferation of the host cell. Macroschizonts develop further into microschizonts and ultimately into merozoites, which are released from the leukocyte. The merozoites invade erythrocytes and develop into piroplasms. Tropical theileriosis is a lymphoproliferative disease in its early phases and is accompanied by enlargement of lymph nodes. On development of pyrexia, a lymphodestructive phase which is associated with a pronounced leukopenia is initiated. The disease is further characterized by a marked anemia (Tait and Hall, 1990).

T. annulata infection is characterized by high fever, weakness, weight loss, inappropriate appetite, conjunctival petechia, enlarged lymph nodes and anaemia. Lateral recumbency, diarrhea and dysentery are also associated with later stages of infection (Radostits et al., 2007). Bos indicus (Zebu cattle) is naturally more resistant to tick infestation as compared to Bos taurus. This tick resistance in Zebu cattle may be due to presence of significantly higher serum complement level in their blood as compared to cross-bred cattle (Wambura et al., 1998).

The ability of indigenous cattle to resist tropical theileriosis, coupled with the fact that cell line vaccination is successful in protecting otherwise susceptible stock, demonstrates that the bovine immune system is capable of mounting an effective response to both initial and subsequent infection. These results suggest that resistant breeds of cattle may possess a degree of innate immunity, while vaccinated exotic stock rely on an acquired response following either vaccination or primary challenge. However, evidence to date indicates that the innate and adaptive bovine immune responses act against both primary and secondary challenge. This contrasts with the situation in $T$. parva, where immunity is afforded principally by the adaptive response of cytotoxic T-cells (Weir, 2006).
Young calves below two months of age were found to be most susceptible to the disease. Cases mainly occurred between the months of March to October every year, coinciding with the period of high activity of the vector ticks (Beniwal et al., 1997). Lower prevalence and milder form of theileriosis in indigenous as compared to cross-bred cattle was believed to be associated with the lower acute phase protein (APP) responses controlled by macrophage cytokines in these animals. There was prolonged elevation of the proinflammatory cytokine dependent APP, $\alpha_{1}-$ glycoprotein (AGP) in exotic and cross-bred cattle, which in contrast was only slightly elevated in the indigenous breed (Glass and Coussens, 2005).

\section{Materials and Methods}

One hundred cattle-calves, out of which 37 cross bred and 63 indigenous, were screened for Theileria annulata infection during October-2015 to September-2016 brought to Teaching Veterinary Clinical Complex, College of Veterinary and Animal Science, Bikaner. Blood samples were collected in ethylene diamine tetra acetic acid (EDTA @ $1 \mathrm{mg} / \mathrm{ml}$ ) vacutainers from all the suspected cattle-calves for genomic DNA isolation. Genomic DNA were isolated using QIAamp ${ }^{\circledR}$ DNA blood mini kit (QIAGEN, GmbH, Germany) as per Procedure. Aliquots of extracted DNA were kept at $-20^{\circ} \mathrm{C}$ and subjected for confirmatory diagnosis by nested polymerase chain reaction (nPCR).

\section{Results and Discussion}

In the present study, prevalence of Theileria annulata infection was higher in cross-bred cattle-calves (51.35 per cent) as compared to indigenous breeds (34.92 per cent). Similar findings were also reported by Beniwal et al., (1997); Glass and Coussens (2005) and Tuli et al., (2015). 
Table.1 Breed related prevalence of Theileria annulata infection in cattle-calves

\begin{tabular}{|c|c|c|c|}
\hline Breed & No. of calves examined & No. of positive calves & Prevalence (\%) \\
\hline Cross bred & 37 & 19 & 51.35 \\
\hline Indigenous & 63 & 22 & 34.92
\end{tabular}

Fig.1 Bar diagram showing breed related prevalence of Theileria annulata infection in cattle-calves

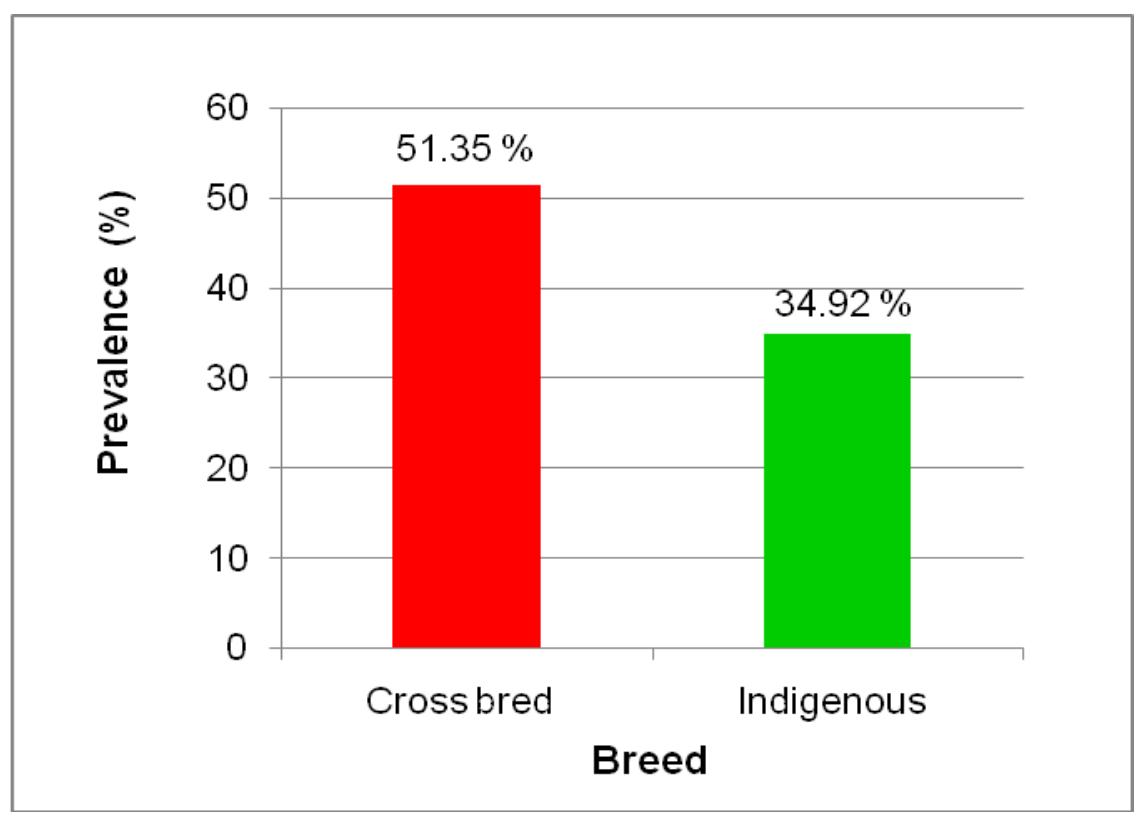

Low prevalence of disease in indigenous as compared to exotic and cross-bred cattle could be due to low acute phase protein (APP) responses controlled by macrophage cytokines in these animals. There is prolonged elevation of the pro-inflammatory cytokine dependent APP, $\alpha_{1}$-glycoprotein (AGP) in exotic and cross-bred cattle, which in contrast is only slightly elevated in the indigenous breed (Glass and Coussens, 2005). Raised levels of $\alpha_{1}$-glycoprotein are associated with chronic inflammatory conditions (Horadagoda et al., 1999) and thus indicative of high systemic levels of pro-inflammatory cytokines in the susceptible breeds. It is believed that APP responses are induced by pro-inflammatory cytokines such as IL-1, IL6 and TNFa (Gabay and Kushner, 1999). Thus it seems likely that Theileria annulata infection will lead to their production. Prevalence is also influenced by cattle breed as cattle usually differ in tick resistance and innate susceptibility to infection (Muhammad et al., 2008). Bos indicus (Zebu cattle) is naturally more resistant to tick infestation as compared to Bos taurus/cross-bred cattle. This may be due to presence of significantly higher complement level in their blood as compared to cross-bred cattle (Wambura et al., 1998). Breed wise prevalence of Theileria annulata infection in cattle-calves is presented in Table 1and Figure 1.

\section{Acknowledgements}

The authors are highly thankful to the Dr. S.K. Kashyap, Professor and Head, Department of Microbiology and 
Biotechnology and Dr. G.C. Gahlot, Professor and Head, Department of Animal Genetics and Breeding, College of Veterinary and Animal Science, Bikaner, Rajasthan for providing necessary facilities to carry out the present investigation. This study is financially supported by the Rajasthan University of Veterinary and Animal Sciences, Bikaner, Rajasthan.

\section{References}

Beniwal, R.K., Nichani, A.K., Sharma, R.D., Rakha, N.K., Sum, D. and Sarup, S. 1997. Responses in animals vaccinated with the Theileria annulata (Hisar) cell culture vaccine. Trop. Anim. Hlth Prod. 29: 109-113.

Durrani, A.Z., Shakoori, A.R. and Kamal, N. 2008. Bionomics of Hyalomma ticks in three districts of Punjab. Pakistan Journal of Animal and Plant Science. 18(1): 20-23.

Erdemir, A., Aktas, M. and Dumanli, N. 2012. Isolation, cloning and sequence analysis of the lactate dehydrogenase gene from Theileria annulata may lead to design of new anti theilerial drugs. Veterinarni Medicina. 57(10): 559-567.

Gabay, C. and Kushner, I. 1999. Mechanisms of disease: Acute phase proteins and other systemic responses to inflammation. New England Journal of Medicine. 340: 448-454.

Gharbi, M., Touay, A., Khayeche, M., Laarif, J., Jedidi, M., Sassi, L. and Darghouth, M.A. 2011. Ranking control options for tropical theileriosis in at-risk dairy cattle in Tunisia, using benefit-cost analysis. Revue scientifique et technique (International Office of Epizootics. 30(3): 763-78.

Glass, E.J. and Coussens, P.M. 2005. Functional genomics of host pathogen interactions in species of veterinary importance. Vet. Immunol. Immunopath. 105: 173-174.

Horadagoda, N.U., Knox, K.M.G., Gibbs, H.A., Reid, S.W.J., Horadagoda, A., Edwards, S.E.R. and Eckersall, P.D. 1999. Acute phase proteins in cattle: discrimination between acute and chronic inflammation. Veterinary Record. 144: 437-441.

Muhammad, G., Naureen, A., Firyal, S. and Saqib, M. 2008. Tick control strategies in dairy production medicine. Pakistan Veterinary Journal. 28(1): 43-50.

Radostits, O.M., Gay, C.C., Hinchcliff, K.W. and Constable, P.D. 2007. Veterinary medicine: A textbook of the diseases of cattle, horses, sheep, pigs and goats, tenth ed. Elsevier, Philadelphia.

Santos, M., Soares, R., Costa, P., Amaro, A., Inacio, J. and Gomes, J. 2013. Revisiting the Tams-1 encoding gene as a species-specific target for the molecular detection of Theileria annulata in bovine blood samples. Ticks Tick-borne Disease. 4: 72-77.

Tait, A. and Hall, F.R. 1990. Theileria annulata: control measures, diagnosis and the potential use of subunit vaccines. Rev. Sci. Tech. off. Int. Epiz. 9(2): 387-403.

Tuli, A., Singla, L.D., Sharma, A., Bal, M.S., Filia, G. and Kaur, P. 2015. Molecular epidemiology, risk factors and haematochemical alterations induced by Theileria annulata in bovines of Punjab (India). Acta Parasitologica. 60(3): 378-390.

Wambura, P.N., Gwakisa, P.S., Silayo, R.S. and Rugaimukamu, E.A. 1998. Breed associated resistance to tick infestation in Bos indicus and their crosses with Bos taurus. Veterinary Parasitology. 77(1): 63-70.

Weir, W. 2006. Genomic and population genetic studies on Theileria annulata. Ph.D. Thesis. Scotland, United Kingdom.

\section{How to cite this article:}

Pavan Goyal and Anju Chahar. 2018. Breed Related Hospital Prevalence of Theileria annulata infection in Cattle-calves Confirmed by Nested Polymerase Chain Reaction in Bikaner District of Rajasthan, India. Int.J.Curr.Microbiol.App.Sci. 7(02): 2767-2770.

doi: https://doi.org/10.20546/ijcmas.2018.702.337 